\title{
Enhancement of Alpha 1-antitrypsin Production in Pichia pastoris by Designing and Optimizing Medium Using Elemental Analysis
}

\author{
Tina Tavasoli ', Sareh Arjmand ${ }^{2}$, Seyed Omid Ranaei Siadat ${ }^{2}$, Seyed Abbas Shojaosadati 1,*, Abbas \\ Sahebghadam Lotfi ${ }^{3}$ \\ ${ }^{1}$ Biotechnology Group, Department of Chemical Engineering, Tarbiat Modares University, Tehran, Iran. \\ ${ }^{2}$ Protein Research Center, Shahid Beheshti University, G.C., Tehran, Iran. \\ ${ }^{3}$ Department of Clinical Biochemistry, Faculty of Medical Science, Tarbiat Modares University, Tehran, Iran. \\ "Corresponding author: Seyed Abbas shojaosadati, Biotechnology Group, Department of Chemical Engineering, Tarbiat Modares University, Tehran, Iran. \\ Tel: +98 21 82883341, Fax: +98 21 82883381, E-mail: shoja_sa@modares.ac.ir
}

Received: 14 April 2016; $\quad$ Revised: 14 Oct. 2016; Accepted: 20 June 2017； Published online: 29 December 2017

\begin{abstract}
Background: Human alpha 1-antitrypsin (AAT) is a monomeric glycosylated protein; it is the potent inhibitor of a whole range of serine proteases and protects tissues against their destructive eff ects. The human plasma-derived AAT, which is currently used to augment the AAT level in patients, is limited due to high cost and source limitation. Recombinant production of AAT can be considered as a potential alternative.

Objectives: This study aims to develop and optimize a new chemically defi ned medium based on an elemental analysis of the yeast Pichia pastoris for an effi cient culture of the recombinant yeast-producing secretory AAT.

Materials and Methods: An elemental analysis of Carbon (C), Hydrogen (H), Nitrogen (N), Sulfur (S); CHNS in its abbreviated form, and metallic elements was performed to determine the exact molecular constituent of the P. pastoris. The medium components were selected according to the obtained formula; they were optimized by the response surface methodology (RSM). The grown yeast cell was measured at the end of $18 \mathrm{~h}$ glycerol batch culture. The amounts of AAT production and elastase inhibitory capacity (EIC) were measured at the end of three days' methanol feeding.

Results: The optimized medium compositions consist of glycerol $\left(40\right.$ g.L. $\left.\mathrm{L}^{-1}\right), \mathrm{KH}_{2} \mathrm{PO}_{4}\left(24.78 \mathrm{~g} . \mathrm{L}^{-1}\right), \mathrm{NaCl},\left(0.88 \mathrm{~g} . \mathrm{L}^{-1}\right)$, $\mathrm{MgSO}_{4} \cdot 7 \mathrm{H}_{2} \mathrm{O}\left(1.95 \mathrm{~g} . \mathrm{L}^{-1}\right),\left(\mathrm{NH}_{4}\right)_{2} \mathrm{SO}_{4}\left(22.76 \mathrm{~g} . \mathrm{L}^{-1}\right)$, and trace elements $\left(20 \mathrm{~mL} . \mathrm{L}^{-1}\right)$. The presented quadratic models show that $\mathrm{KH}_{2} \mathrm{PO}_{4}$ and (NH4) $\mathrm{SO}_{4}$ are the most abundant ones in the P. pastoris biomass and have the greatest eff ect on the cell growth, EIC, and AAT protein production responses.

Conclusions: According to the results of this study, it can be concluded that the characterizing cell composition formula could be considered as an appropriate method to design culture media in order to improve cell growth and productivity. Compared to the common P. pastoris chemically defi ned media, FM22 and BSM, production of AAT protein increased by 1.5 and 1.4 times, respectively, in this new medium.
\end{abstract}

Keywords: Alpha 1-antitrypsin, Designing Medium, Elemental Analysis, Medium Optimization, Pichia pastoris.

\section{Background}

AAT protein is the most abundant protease inhibitor in human circulation; it is mainly produced in the liver and secreted to the bloodstream $(1,2)$. This protein is introduced as the archetype of the serpin protease inhibitor (serpin) superfamily (3). AAT is a potent inhibitor of the multiple serine proteases, including elastase, trypsin, and proteinase 3 , as well as some nonserine proteases such as aggrecanase and metalloprotease MMP9; it balances the action of substrate proteases in different tissues (mainly neutrophil proteases in the lung) (4). The average level of AAT in the blood is $1.3 \mathrm{mg} \cdot \mathrm{mL}^{-1}$. Individuals with AAT levels less than $15 \%$ of the normal are considered AAT-deficient. They are likely to develop panacinar emphysema or chronic obstructive pulmonary disease (COPD) at young ages $(2,3,5)$. AAT protein augmentation is the only specific therapy for lung diseases related to the AAT deficiency. For this purpose, purified AAT protein is administered by a weekly intravenous infusion throughout the patient's life to boost the AAT level in the blood. All the currently available commercial AAT proteins are

Copyright (C) 2017 The Author(s); Published by National Institute of Genetic Engineering and Biotechnology. This is an open access article, distributed under the terms of the Creative Commons Attribution-NonCommercial 4.0 International License (http://creativecommons.org/licenses/ by-nc/4.0/) which permits others to copy and redistribute material just in noncommercial usages, provided the original work is properly cited. 
derived from human plasma. Despite being effective, this drug suffers from the considerable limitations that include the risk of viral infection, source limitation, and high cost for patients and their families $(6,7)$. The production of the recombinant AAT can be considered a notable solution for these problems. Hence, different studies have shown the production of AAT in different hosts; from bacteria to animal cells (8-15).

The Methylotrophic yeast $P$. pastoris is an attractive host for the production of the many human glycoproteins like AAT. This host benefits from advantages such as rapid growth to very high cell densities, presence of tightly regulated alcohol oxidase 1 (AOX1) promoter, efficient secretion machinery system, ease of genetic manipulation, and the capacity ofintroducing many posttranslational modifications $(13,16)$.

The level of expression of a heterologous protein in a host depends on multiple variables specific to the protein's characteristics and the host. Such variables should be carefully evaluated during the development of a bioprocess. Different techniques for optimizing the gene copy number, codon preference, enhancing mRNA stability, promoter selection, using fusion proteins, and many other gene manipulation practices have been explored to improve the process of producing different heterologous proteins in the yeasts. Optimization the yeast culture conditions and the media compositions are another traditional techniques to achieve a high cell density for the high-level of production, as well as for improving the stability of the recombinant protein, and consequently maximizing the profitability.

The culture medium is a key player when a high cell density for any microorganism is desired. The most common growth culture media for achieving a high cell density for $P$. pastoris are the basal salt medium (BSM) proposed by Invitrogen Co, FM22 formulated by Stratton et al., and the medium reported by D'Anjou and Daugulis. BSM and FM22 media generally provide a high concentration of the basic elements, while the D'Anjou medium has a low concentration of the chemical elements and thus is associated with some problems including precipitation, imbalanced composition, and undesirable ionic strength $(16,17)$. Nitrogen source, which is one of the most important elements to formulate a medium, in BSM and FM22 is also employed to adjust the $\mathrm{pH}$. Hence, nitrogen starvation may occur during the high cell density cultivation of the $P$. pastoris, which would directly increase proteolysis events and degradation of the extracellular proteins. On the other hand, it is necessary to avoid its accumulation because it can provoke the inhibition of the growth and enlarge the lag phase
(16). To reduce the problems associated with the current media, it is important to design and optimize a new medium for the biomass generation and an efficient production of the recombinant $P$. pastoris. The necessary amount of each nutrient source is variable for the different microorganisms; it should be calculated on the basis of the mass balance for the cell growth and product formation (18). Most studies do not address the design of the culture medium and only deal with the optimization of the existing successful culture medium.

\section{Objectives}

This study aims to formulate a new culture medium by using an elemental analysis of $P$. pastoris cells. It also aims to optimize each component to reach the high cell density of the recombinant $P$. pastoris and to maximize the secretory production of the AAT by using the RSM.

\section{Materials and Methods}

\subsection{Microorganism, Media, and Culture Conditions}

Recombinant $P$. pastoris, which expresses AAT under the control of the AOX1 promoter with the $\mathrm{Mut}^{+}$ phenotype was obtained from the previous study (8). The primary culture medium used for the cultivation of the P. pastoris for CHNS and the elemental analysis of the cells was YPG (yeast extract $\left(10 \mathrm{~g} . \mathrm{L}^{-1}\right)$, peptone (20 g. $\left.\mathrm{L}^{-1}\right)$ and glycerol $\left(20\right.$ g. $\left.\mathrm{L}^{-1}\right)$ ). Other culture media used for the optimization of the medium, AAT production quantity, and function assays were obtained in accordance with the experimental design explained in the following sections. Yeast cells were cultivated at $200 \mathrm{RPM}$ and $30^{\circ} \mathrm{C}$.

All experiments were performed in $250 \mathrm{~mL}$ Erlenmeyer flasks with $50 \mathrm{~mL}$ of working mediumand 40 g. $\mathrm{L}^{-1}$ of the glycerol as a carbon and energy source. Inoculation into the flasks was done in such a way that the initial optical density at $600 \mathrm{~nm}$ was the same for all experiments.

\subsection{Induction of AAT Production}

After $20 \mathrm{~h}$ of cultivation in YPG, the culture was centrifuged for $5 \mathrm{~min}$ at $5000 \times \mathrm{g}$ and the medium was substituted with a new inductive one containing $0.5 \%$ of the pure methanol to initiate AAT production. The inductive condition was maintained for $72 \mathrm{~h}$ with the addition of $1 \%$ methanol every $24 \mathrm{~h}$ (19-21).

\subsection{Elemental Analysis}

For CHNS analysis, the yeast cells at the end of the log phase of the growth of the YPG medium was separated and dried at $80^{\circ} \mathrm{C}$ for $18 \mathrm{~h}$. The $\mathrm{C}, \mathrm{H}, \mathrm{N}$, and $\mathrm{S}$ elemental analysis of the yeast biomass was performed on an 
Elemental CHNS Analyzer model, Vario EL III (Varion EL, Elementar Analyzer system GmbH, Germany).

The composition of the mineral elements was determined using SPECRTO ARCOS ICP-OES (SPECTRO, Germany). For this purpose, fresh yeast biomass was digested with aqua regia (nitric acid/ hydrogen chloride [1:3]) for $45 \mathrm{~min}$ at $80^{\circ} \mathrm{C}$. The digested solution was passed through the cellulose acetate membrane filters $(0.45 \mu \mathrm{m})$ before being analyzed by ICP-OES.

\subsection{Determination of Yeast Biomass}

The yeast biomass was determined by $\mathrm{OD}_{600}$ measurements using the BiochromUltrospec 60 spectrophotometer $\left(1 \mathrm{OD}_{600}\right.$ unit is equivalent to $0.25 \mathrm{~g}$ DCW.L-1), data were not shown).

\subsection{Assessment of AAT Activity}

The activity of the produced recombinant AAT in the different media was determined by the elastase inhibition assay according to the previously described method (22) with slight modifications. N-SuccinylAla (3)- $\rho$-nitroanilide (S4760, Sigma) was used as an elastase substrate. As much as $100 \mu \mathrm{L}$ of the each culture supernatant was dissolved in $0.2 \mathrm{M}$ Tris- $\mathrm{HCl}$ buffer ( $\mathrm{pH}$ 8.0) and was incubated with 0.01 (Unit. $\mathrm{mL}^{-1}$ ) elastase (Cat \#45124, Sigma) for $5 \mathrm{~min}$, before adding 0.07 (mg.mL ${ }^{-1}$ ) substrate in the final volume of $300 \mu \mathrm{L}$. The substrate hydrolysis and the release of $p$-nitroaniline were measured by the spectrophotometer at $410 \mathrm{~nm}$ after $15 \mathrm{~min}$ at $25^{\circ} \mathrm{C}$. EIC was expressed as a percentage of the enzyme activity inhibited by the recombinant AAT compared with the blank vial (without AAT).

\subsection{AAT Quantification}

The secreted AAT was determined at the end of each experiment by using the human Serpin A1 DuoSet Kit (DY1268, R\&D Systems), according to the manufacturer's instructions. All the samples were diluted equally in the diluents buffer $(0.05 \%(\mathrm{v} / \mathrm{v})$ Tween 20 in PBS, pH 7.2-7.4) and assayed in triplicates. The Recombinant Human Serpin A1 was applied as the standard sample.

\subsection{RSM Experimental Design and Statistical Analysis}

A central composite design (CCD) was used in the optimization of the culture medium components for maximizing AAT production. The concentrations of [g.L $\left.{ }^{-1}\right]\left(\mathrm{KH}_{2} \mathrm{PO}_{4}, \mathrm{NaCl}, \mathrm{MgSO}_{4} .7 \mathrm{H}_{2} \mathrm{O},\left(\mathrm{NH}_{4}\right)_{2} \mathrm{SO}_{4}\right.$ and trace elements solution (mL. $\mathrm{L}^{-1}$ ) in the medium were independent variables optimized at five different levels $(-\alpha,-1,0,+1,+\alpha)$. As dependent variables, biomass production at the end of glycerol batch phase, EIC results, and the quantity of the produced AAT at the end of the methanol-feeding step was considered as responses. A total of 50 experimental runs, including eight replicates for the centre point, were performed. The role of each variable and their interaction is explained by applying the following quadratic Eq. (1):

$Y=\beta_{0}+\sum_{i=1}^{k} \beta_{\mathrm{i}} x_{i}+\sum_{i=1}^{k} \beta_{\mathrm{ii}} x_{i}^{2}+\sum_{i} \sum_{j} \beta_{\mathrm{ij}} x_{i} x_{j}+\varepsilon$

where $k, \beta \beta_{0}, \beta \beta_{\mathrm{i}}, x_{i}, \beta \beta_{\mathrm{ii}}, \beta \beta_{\mathrm{ij}}$ and $\varepsilon \varepsilon$ represent the number of variables, the constant term, coefficients of the linear parameters, variables, coefficients of the quadratic parameters, coefficients of the interaction parameters, and residuals associated with the experiments, respectively.

\section{Results}

\subsection{Elemental Composition of P. pastoris and Medium Formulation}

To formulate a new appropriate medium, the components concentration should be optimized based on cell composition, growth stoichiometry, product formation, yield coefficient, and other parameters. Medium culture composition must supply the required energy to support cells' maintenance as well as cell growth and metabolite production. At the first step, the equation (Eq. 2) is written on the basis of the mass balance for cell growth and product formation.

Carbon + energy + Nitrogen $+\mathrm{O} 2+$ Other requirements $\rightarrow$ Biomass + Products $+\mathrm{CO} 2+\mathrm{H} 2 \mathrm{O}+$ Heat

Quantitative calculation of the above formula is a helpful method to minimize the surplus or shortage of the culture medium ingredients during the fermentation process. Therefore, the concentration range of such components was determined based on the minimum amount needed for the optimal biomass production. The required substrates' concentrations can be estimated by knowing how much biomass is needed for the product formation. In this study, to design a new efficient chemically defined media, the macro and micro elemental compositions of the $P$. pastoris yeast cells were determined by using two elemental analysis techniques, namely CHNS and ICP-OES analysis. These two analytical methods are excellent tools for providing the elemental composition of different cells and determining their empirical formula $(23,24)$.

The CHNS analysis was used to quantify the mass 
Tavasoli T et al.

Table1. CHNS analysis of the dried P. pastoris material.

\begin{tabular}{lcc}
\hline Element name & Weight $(\mathbf{m g})$ & Weight $(\%)$ \\
\hline Nitrogen & 0.72 & 7.9 \\
Carbon & 4.09 & 44.6 \\
Hydrogen & 0.59 & 6.5 \\
Sulfur & 0.038 & 0.42 \\
\hline
\end{tabular}

fraction and determination of the ratio of main macro elements; carbon, nitrogen, hydrogen, and sulfur (Table 1). The ICP-OES analysis was used to determine the mass fraction of the trace elements including $\mathrm{Mg}, \mathrm{S}$, $\mathrm{K}, \mathrm{Ca}, \mathrm{Na}, \mathrm{Fe}, \mathrm{P}, \mathrm{Co}, \mathrm{Zn}, \mathrm{Cu}, \mathrm{Pb}$, and $\mathrm{Mn}$ (Table 2). The quantities of the shared sulfur elements in the two analyses were used to link their results and to determine the $P$. pastoris chemical formula, while the oxygen was determined by the difference. The ultimate formula of P. pastoris, based on the ICP and CHNS analysis, is shown below:

$$
\mathrm{CH}_{1.7} \mathrm{~N}_{0.15} \mathrm{O}_{0.55} \mathrm{~S}_{0.0032} \mathrm{~K}_{0.038} \mathrm{P}_{0.022} \mathrm{Na}_{0.0012} \mathrm{Mg}_{0.001}
$$

According to this chemical formula, the molar weight of $P$. pastoris is about $30 \mathrm{~g}$; therefore, $3.3 \mathrm{~mol}$ of $P$. pastoris is needed to produce $100 \mathrm{~g}$ of biomass dry weight (DW). Based on these analyses, the quantities of the components for obtaining $100 \mathrm{~g}$ of DCW $P$. pastoris and related medium optimization by the RSM methodology is shown in Table 3.

According to the literature, mineral salts of $\left(\mathrm{NH}_{4}\right)_{2} \mathrm{SO}_{4}, \mathrm{NaCl}, \mathrm{MgSO}_{4} \cdot 7 \mathrm{H}_{2} \mathrm{O}$, and $\mathrm{KH}_{2} \mathrm{PO}_{4}$ were selected to supply nitrogen, phosphorus, sulfur, potassium, magnesium, and sodium elements (25).

A new trace metal elements solution $\left(\mathrm{FeSO}_{4} \cdot 7 \mathrm{H}_{2} \mathrm{O}\right.$ (12 g.L $\left.\mathrm{L}^{-1}\right), \mathrm{ZnCl}_{2}\left(13 \mathrm{~g} . \mathrm{L}^{-1}\right), \mathrm{CuSO}_{4} \cdot 5 \mathrm{H}_{2} \mathrm{O}\left(5 \mathrm{~g} \cdot \mathrm{L}^{-1}\right), \mathrm{CaCl}_{2}$ $\left(0.9\right.$ g. $\left.\mathrm{L}^{-1}\right), \mathrm{MnSO}_{4} \cdot \mathrm{H}_{2} \mathrm{O}\left(4.5 \mathrm{~g} . \mathrm{L}^{-1}\right)$, and $\left.5 \mathrm{~mL} \mathrm{H}_{2} \mathrm{SO}_{4}\right)$ was formulated according to the obtained $P$. pastoris formula and then analyzed applying RSM to find the best quantity of this solution in the culture medium for the selected responses.

\subsection{Experimental Design and Statistical Analysis}

Using the CCD-RSM methodology, 32 factorial points, 10 axial points, and eight central point experiments were designed to obtain the optimum quantity of the medium compositions and to optimize the culture medium. The experimental design and responses (the optical density of the culture media at $600 \mathrm{~nm}$, the percentage of elastase inhibition, and production quantity of ATT) are indicated in Table 4. The analysis of variance (ANOVA) was used to evaluate the effect of each factor at $\mathrm{OD}_{600}$, elastase inhibitory capacity, and AAT production. The ANOVA Table in all the three responses shows that the results were very similar. To avoid repetition, the results were reported based on the production of the AAT. According to the ANOVA (Table 5), a quadratic model is appropriate for explaining the effect of the culture media components on the responses. This quadratic model is shown in Eq. 3, where A B, C, D, and E are independent variables.

Production of $A A T=6.99+1.51 A-0.14 B-0.36 C+0.72 D$
$+0.17 E-0.26 A B+0.28 A D$

Table 2. The elemental composition of the P. pastoris by analysis of ICP-OES.

\begin{tabular}{lccc}
\hline Element & $\begin{array}{c}\text { Amount } \\
\left(\mathrm{g} . \mathrm{Kg}^{-1} \mathrm{DCW}\right)\end{array}$ & Element & $\begin{array}{c}\text { Amount } \\
\left(\mathrm{g} . \mathrm{Kg}^{-1} \mathrm{DCW}\right)\end{array}$ \\
\hline Sulfur & 4 & Copper & 0.1 \\
Magnesium & 1.25 & Iron & 0.2 \\
Potassium & 29.2 & Manganese & 0.07 \\
Sodium & 1.87 & Zinc & 0.25 \\
Phosphorus & 25.7 & Calcium & 0.82 \\
Lead & 0.0023 & Cobalt & 0.005 \\
\hline
\end{tabular}

Table 3. Factors and their levels in the central composite design for a medium culture optimization.

\begin{tabular}{lccccccc}
\hline Chemicals & Symbol & Required concentration & $\boldsymbol{- \alpha}$ & $\mathbf{- 1}$ & $\mathbf{0}$ & $\mathbf{1}$ & $\mathbf{A}$ \\
\hline $\mathrm{KH}_{2} \mathrm{PO}_{4}$ & $\mathrm{~A}$ & $19.2 \mathrm{~g} . \mathrm{L}^{-1}$ & 12.00 & 17.21 & 21.00 & 24.78 & 30.00 \\
$\mathrm{NaCl}$ & $\mathrm{B}$ & $0.9 \mathrm{~g} . \mathrm{L}^{-1}$ & 0.50 & 0.79 & 1.00 & 1.21 & 1.50 \\
$\mathrm{MgSO}_{4} \cdot 7 \mathrm{H}_{2} \mathrm{O}$ & $\mathrm{C}$ & $2 \mathrm{~g} . \mathrm{L}^{-1}$ & 1.50 & 1.93 & 2.25 & 2.56 & 3.00 \\
$(\mathrm{NH} 4)_{2} \mathrm{SO}_{4}$ & $\mathrm{D}$ & $12 \mathrm{~g} . \mathrm{L}^{-1}$ & 5.00 & 12.24 & 17.50 & 22.76 & 30.00 \\
Trace element & E & $20 \mathrm{~mL} \cdot \mathrm{L}^{-1}$ & 10.00 & 15.80 & 20.00 & 24.20 & 30.00 \\
\hline
\end{tabular}


Tavasoli T et al.

Table 4. Levels of the variables and CCD for production quantity of AAT.

\begin{tabular}{|c|c|c|c|c|c|c|c|c|}
\hline \multirow[b]{2}{*}{ RUN } & \multirow[b]{2}{*}{$\begin{array}{c}\mathrm{KH}_{2} \mathrm{PO}_{4} \\
\text { g. } \mathbf{L}^{-1}\end{array}$} & \multirow[b]{2}{*}{$\begin{array}{l}\mathrm{NaCl} \\
\text { g.L } \mathrm{L}^{-1}\end{array}$} & \multirow[b]{2}{*}{$\begin{array}{c}\mathrm{MgSO}_{4} \cdot 7 \mathrm{H}_{2} \mathrm{O} \\
\text { g. } \mathrm{L}^{-1}\end{array}$} & \multirow[b]{2}{*}{$\begin{array}{c}\left(\mathrm{NH}_{4}\right)_{2} \mathrm{SO}_{4} \\
\text { g.L. }\end{array}$} & \multirow[b]{2}{*}{$\begin{array}{c}\text { Trace Element } \\
\text { mL. } \mathbf{L}^{-1}\end{array}$} & \multicolumn{3}{|c|}{ Responses } \\
\hline & & & & & & Optical Density & $\begin{array}{c}\text { EIC } \\
\%\end{array}$ & $\begin{array}{l}\text { AAT Production } \\
\left(\mathrm{mg}^{\left.-\mathrm{L}^{-1}\right)}\right.\end{array}$ \\
\hline 1 & 24.8 & 0.79 & 2.57 & 12.24 & 15.8 & 9.6 & 60 & 6.4 \\
\hline 2 & 17.2 & 0.79 & 1.93 & 12.24 & 24.2 & 8.6 & 46 & 5.4 \\
\hline 3 & 24.8 & 1.21 & 2.57 & 12.24 & 24.2 & 9.6 & 65 & 8.5 \\
\hline 4 & 24.8 & 0.79 & 1.93 & 12.24 & 24.2 & 9.6 & 64 & 9.5 \\
\hline 5 & 17.2 & 1.21 & 2.57 & 22.76 & 15.8 & 10.5 & 47 & 5.2 \\
\hline 6 & 17.2 & 0.79 & 2.57 & 12.24 & 24.2 & 8.5 & 43 & 5.3 \\
\hline 7 & 21 & 1 & 3 & 17.5 & 20 & 11.2 & 65 & 6.3 \\
\hline 8 & 17.2 & 0.79 & 2.57 & 22.76 & 15.8 & 10.5 & 58 & 6.2 \\
\hline 9 & 21 & 1.5 & 2.25 & 17.5 & 20 & 10.6 & 60 & 6.6 \\
\hline 10 & 12 & 1 & 2.25 & 17.5 & 20 & 9.6 & 35 & 3.2 \\
\hline 11 & 24.8 & 0.79 & 2.57 & 12.24 & 24.2 & 9.6 & 64 & 7.7 \\
\hline 12 & 24.8 & 0.79 & 2.57 & 22.76 & 24.2 & 10.5 & 62 & 8.3 \\
\hline 13 & 24.8 & 0.79 & 1.93 & 12.24 & 15.8 & 9.6 & 67 & 9.3 \\
\hline 14 & 24.8 & 1.21 & 1.93 & 12.24 & 15.8 & 9.6 & 56 & 6.5 \\
\hline 15 & 21 & 1 & 2.25 & 17.5 & 20 & 12 & 58 & 6.6 \\
\hline 16 & 21 & 1 & 2.25 & 17.5 & 20 & 12.2 & 62 & 7.7 \\
\hline 17 & 17.2 & 1.21 & 2.57 & 12.24 & 24.2 & 8.6 & 45 & 5.3 \\
\hline 18 & 17.2 & 1.21 & 1.93 & 22.76 & 24.2 & 10.5 & 51 & 6.3 \\
\hline 19 & 24.8 & 1.21 & 2.57 & 12.24 & 15.8 & 9.6 & 54 & 6 \\
\hline 20 & 21 & 1 & 2.25 & 17.5 & 30 & 11.2 & 56 & 7 \\
\hline 21 & 17.2 & 0.79 & 2.57 & 12.24 & 15.8 & 8.6 & 39 & 4.2 \\
\hline 22 & 21 & 1 & 2.25 & 17.5 & 20 & 12.2 & 60 & 7.1 \\
\hline 23 & 21 & 1 & 2.25 & 17.5 & 20 & 12.2 & 64 & 8.9 \\
\hline 24 & 24.8 & 0.79 & 2.57 & 22.76 & 15.8 & 11.6 & 67 & 9.2 \\
\hline 25 & 21 & 1 & 2.25 & 5 & 20 & 6.6 & 48 & 5.4 \\
\hline 26 & 21 & 0.5 & 2.25 & 17.5 & 20 & 10.6 & 52 & 6.8 \\
\hline 27 & 17.2 & 1.21 & 2.57 & 12.24 & 15.8 & 8.6 & 48 & 4.9 \\
\hline 28 & 24.8 & 1.21 & 1.93 & 22.76 & 24.2 & 10.5 & 69 & 9.9 \\
\hline 29 & 21 & 1 & 2.25 & 17.5 & 20 & 12.2 & 62 & 7.6 \\
\hline 30 & 24.8 & 1.21 & 1.93 & 22.76 & 15.8 & 10.5 & 67 & 9.7 \\
\hline 31 & 17.2 & 1.21 & 1.93 & 22.76 & 15.8 & 10.5 & 58 & 6.7 \\
\hline 32 & 17.2 & 0.79 & 1.93 & 12.24 & 15.8 & 8.6 & 38 & 4.6 \\
\hline 33 & 17.2 & 0.79 & 1.93 & 22.76 & 15.8 & 10.5 & 50 & 5.5 \\
\hline 34 & 17.2 & 1.21 & 1.93 & 12.24 & 15.8 & 8.6 & 46 & 4.7 \\
\hline 35 & 21 & 1 & 2.25 & 17.5 & 10 & 11.2 & 62 & 7.3 \\
\hline 36 & 24.8 & 1.21 & 1.93 & 12.24 & 24.2 & 9.6 & 52 & 6.8 \\
\hline 37 & 24.8 & 0.79 & 1.93 & 22.76 & 24.2 & 11.6 & 71 & 10.8 \\
\hline 38 & 24.8 & 1.21 & 2.57 & 22.76 & 15.8 & 11.6 & 52 & 7.6 \\
\hline 39 & 17.2 & 0.79 & 1.93 & 22.76 & 24.2 & 10.5 & 55 & 5.8 \\
\hline 40 & 17.2 & 1.21 & 1.93 & 12.24 & 24.2 & 8.6 & 46 & 5.5 \\
\hline 41 & 30 & 1 & 2.25 & 17.5 & 20 & 11.6 & 65 & 9.4 \\
\hline 42 & 24.8 & 0.79 & 1.93 & 22.76 & 15.8 & 11.6 & 67 & 10.5 \\
\hline 43 & 21 & 1 & 1.5 & 17.5 & 20 & 11.2 & 51 & 7.5 \\
\hline 44 & 21 & 1 & 2.25 & 17.5 & 20 & 12.2 & 60 & 6.7 \\
\hline 45 & 21 & 1 & 2.25 & 17.5 & 20 & 12.2 & 60 & 6.9 \\
\hline 46 & 21 & 1 & 2.25 & 30 & 20 & 10.4 & 66 & 9.6 \\
\hline 47 & 24.8 & 1.21 & 2.57 & 22.76 & 24.2 & 10.5 & 68 & 9.8 \\
\hline 48 & 17.2 & 1.21 & 2.57 & 22.76 & 24.2 & 10.5 & 32 & 5 \\
\hline 49 & 21 & 1 & 2.25 & 17.5 & 20 & 12.2 & 58 & 6.8 \\
\hline 50 & 17.2 & 0.79 & 2.57 & 22.76 & 24.2 & 10.6 & 50 & 5.2 \\
\hline
\end{tabular}


Tavasoli T et al.

Table 5. ANOVA analysis for the response surface model.

\begin{tabular}{lccccc}
\hline Source & Sum of squares & DF & Mean squares & F-Value & P-Value \\
\hline Model & 141.82 & 20 & 7.09 & 12.99 & $<0.0001$ \\
$\mathrm{KH}_{2} \mathrm{PO}_{4}$ & 98.92 & 1 & 98.92 & 181.25 & $<0.0001$ \\
$\mathrm{NaCl}$ & 0.82 & 1 & 0.82 & 1.51 & 0.21 \\
$\mathrm{MgSO}_{4} \cdot 7 \mathrm{H}_{2} \mathrm{O}$ & 5.6 & 1 & 5.6 & 10.26 & 0.0033 \\
$(\mathrm{NH} 4)_{2} \mathrm{SO}_{4}$ & 22.31 & 1 & 22.31 & 40.88 & $<0.0001$ \\
Trace element & 1.19 & 1 & 1.19 & 2.18 & 0.15 \\
\hline
\end{tabular}

The fit of the model was checked by the coefficient of determination $\mathrm{R}^{2}$, which was calculated to be 0.93 , indicating that $93 \%$ of the variability in the response could be explained by the model. The relatively high value of $\mathrm{R}^{2}$ indicates that the quadratic model fits the data under these experimental conditions. The model's $F$-Value of 12.96 implies that the model was significant. The significance of each component was evaluated by using $\mathrm{P}$-value, which was also very low $(P<0.0001)$, thus indicating the significance of the model (26-28). The response surface curve was plotted in order to determine the optimum level of each variable for the maximum response. The response surface curves are shown in Figures 1 and 2. Each Figure demonstrates the effect of the two factors, while the other factors are fixed at the middle level.

\subsection{Optimized Medium and Validation of Experimental Model}

The model predicted the optimal values with the desirability of $96 \%$, where the values were $\mathrm{KH}_{2} \mathrm{PO}_{4}$ (24.78 g.L $\left.{ }^{-1}\right), \mathrm{NaCl},\left(0.88\right.$ g. $\left.\mathrm{L}^{-1}\right), \mathrm{MgSO}_{4} \cdot 7 \mathrm{H}_{2} \mathrm{O}(1.95$ g.L $\left.\mathrm{L}^{-1}\right),\left(\mathrm{NH}_{4}\right)_{2} \mathrm{SO}_{4}\left(22.76\right.$ g.L. $\left.\mathrm{L}^{-1}\right)$ and trace element $(20$ $\left.\mathrm{mL} \cdot \mathrm{L}^{-1}\right)$. A verification experiment was performed by

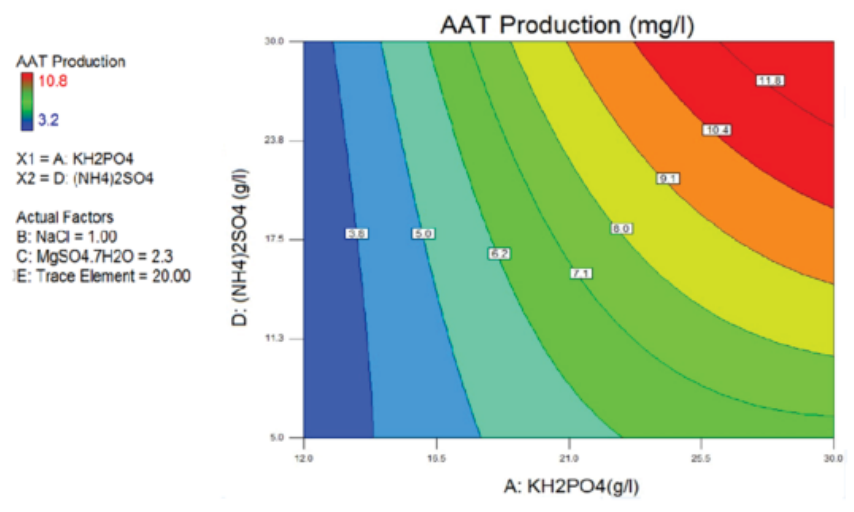

Figure 1. Contour plot for the effect of $\left(\mathrm{NH}_{4}\right)_{2} \mathrm{SO}_{4}$ and $\mathrm{KH}_{2} \mathrm{PO}_{4}$ on the production quantity of AAT. using the predicted optimum medium composition, while the AAT production was measured to be 10.3 (mg. $\mathrm{L}^{-1}$ ) very close to the predicted response 10.6 (mg.L $\mathrm{L}^{-1}$ ). This amount of production was 1.5 and 1.4 times higher than the current chemically defined media FM22 and BSM, respectively (data was not shown). Hence, the validity of the proposed quadratic model and the success of the optimization are approved.

\section{Discussion}

The components of the medium can significantly affect cell growth, yield, and volumetric productivity, and hence it is critically important to design an optimized medium. Designing the medium is a challenging, laborious, and time-consuming process comprising many experiments. However, the new media is frequently designed in the industry and the research lab because new strains are continuously being introduced and optimization of the existing media for the established strains can be very beneficial commercially. There are many techniques for designing and optimizing media including literature search, component swapping, one at a time, biological mimicry, statistical, and mathematical techniques like an experimental
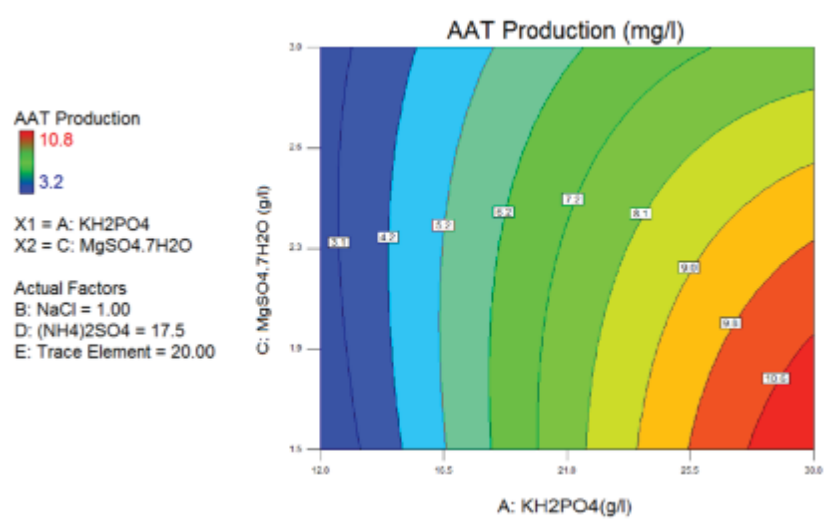

Figure 2. Contour plot for the effect of $\mathrm{MgSO}_{4} \cdot 7 \mathrm{H}_{2} \mathrm{O}$ and $\mathrm{KH}_{2} \mathrm{PO}_{4}$ on the production quantity of AAT. 
design. Here, we used a combination of the biological mimicry and experimental design to get better results (29). The biological mimicry, also known as 'match and win strategy', is a close-ended system that is based on the concept that the medium provides the best growth and productivity while containing the right proportion of everything that the cells need. In this method, the elemental composition analysis of the host cell and desired product concentration is required. We considered this strategy as a good starting point for designing a new efficient medium. To the best of our knowledge, this is the first time that the strategy is used to formulate a new medium for the growth and production of the P. pastoris.

The ANOVA results and the mathematical model indicate that $\mathrm{KH}_{2} \mathrm{PO}_{4}$ and $\left(\mathrm{NH}_{4}\right)_{2} \mathrm{SO}_{4}$ have the most positive effect on the AAT production quantity. The positive effect of these components could be attributed to their elemental compositions. The interaction effect between the factors was tested by using contour plots for the possible combinations of the factors while keeping other factors constant at the middle level. $\mathrm{KH}_{2} \mathrm{PO}_{4}$ and $\left(\mathrm{NH}_{4}\right)_{2} \mathrm{SO}_{4}$ contain elements of nitrogen, hydrogen, and sulfur, which are the most abundant elements after carbon, in $P$. pastoris. These results are in agreement with the CHNS and ICP-OES analyses $(30,31)$. Increasing $\mathrm{MgSO}_{4} \cdot 7 \mathrm{H}_{2} \mathrm{O}$ has a slight negative effect on the quantity of AAT production. Magnesium is the most abundant intracellular divalent cation in all living cells, including yeasts, and plays numerous structural and functional roles in the yeast cell physiology. This metal acts as the essential cofactor for a wide range of enzymes that are involved in different metabolic and bioenergetics pathways and are critical for the production of the proteins (32). However, it has been known that high concentrations of magnesium ion stabilize ribosome-bound tRNAs and result in ribosome stalling and slow translation rate along with the protein biosynthesis (33). This fact could be an explanation for our case, which needs further study.

Any change in the $\mathrm{NaCl}$ concentrations within the selected range has no effect on the AAT production. These results were exactly equivalent to the cell growth (34). Compared with the other trace metal elements solutions which were introduced for the P. pastoris so far, the presented trace metal solution formulated in accordance with the $P$. pastoris formula is simpler with fewer components. Such simplicity has several benefits such as the lack of precipitation problem, prevention of the possible interference with the excess metals in the downstream processing, and reduction of the metal waste disposals for the sake of environmental protection $(26,35)$.

\section{Conclusion}

In this study, a unique and new culture medium has been developed for P. pastoris to enhance its growth and productivity. An elemental analysis strategy was used as the starting point to select the culture medium components according to the cell formulation. Next, the RSM methodology was successfully used to investigate the component interaction effects and obtaining an optimized concentration of the each elemental constituent. Thus, a newly promoted medium has been introduced with the considerable advantages including fewer components and easy preparation, lack of precipitation problem, no need for acid or base to adjust the initial $\mathrm{pH}$, no heavy metal elements in the trace elements solution. Compared to the common chemically defined media for $P$. pastoris, namely FM22 and BSM, the production of AAT protein increased by 1.5 and 1.4 times respectively in this new medium. According to the results of the presented study, it can be concluded that the characterizing cell composition formula could be considered as an appropriate method for designing culture media in order to improve cell growth and productivity.

\section{Acknowledgment}

This work was supported by the Shahid Beheshti University's Protein Research Center of Iran (G. C.). As well, the authors are grateful to the Stat-Ease Minneapolis, MN, USA, for providing us with the Design-Expert 7.1.4 package.

\section{References}

1. Lewis EC. Expanding the clinical indications for alpha(1)antitrypsin therapy. MolMed. 2012;18(1):957-70. DOI: 10.2119/ molmed.2011.00196.

2. Janciauskiene SM, Bals R, Koczulla R, Vogelmeier C, Köhnlein $\mathrm{T}$, Welte T. The discovery of $\alpha 1$-antitrypsin and its role in health and disease. Res Med. 2011;105(8):1129-39. DOI:10.1016/j. rmed.2011.02.002.

3. Karnaukhova E, Ophir Y, Golding B. Recombinant human alpha-1 proteinase inhibitor: towards therapeutic use. Amino Acids. 2006;30(4):317-32. DOI 10.1007/s00726-005-0324-4.

4. Wewers MD, Crystal RG. Alpha-1 Antitrypsin Augmentation Therapy. COPD. 2013;10(S1):64-7. DOI: 10.3109/15412555.2013.764402.

5. Wood AM, Stockley RA. Alpha One Antitrypsin Deficiency: From Gene to Treatment. Respiration, 2007;74(5):481-92. DOI: $10.1159 / 000105536$.

6. Lomas DA, Li-Evans D, Finch JT, Carrell RW. The mechanism of $\mathrm{Z} \alpha 1$-antitrypsin accumulation in the liver. Nature. 1992;357(6379):605-7. DOI:10.1038/357605a0.

7. Greulich T, Nell C, Herr C, Vogelmeier C, Kotke V, Wiedmann $\mathrm{S}$, et al. Results from a large targeted screening program for alpha-1-antitrypsin deficiency: 2003-2015. OJRD. 2016;11:75. DOI: $10.1186 / \mathrm{s} 13023-016-0453-8$. 
8. Arjmand S, Bidram E, Lotfi AS, Shamsara M, Mowla SJ. Expression and Purification of Functionally Active Recombinant Human Alpha 1-Antitrypsin in Methylotrophic Yeast Pichia pastoris. Avicenna J Med Biotech. 2011;3(3):12734.PMCID: PMC3558188.

9. Massoud M, Bischoff R, Dalemans W, Pointu H, Attal J, Schultz $\mathrm{H}$, et al. Expression of active recombinant human $\alpha 1$-antitrypsin in transgenic rabbits. $J$ Biotechnol. 1991;18(3):193-204. DOI:10.1016/0168-1656(91)90247-S.

10. Carver A, Wright G, Cottom D, Cooper J, Dalrymple M, Temperley S, et al. Expression of human alpha 1 antitrypsin in transgenic sheep. Cytotechnology. 1992;9(1-3):77-84. PMID:1369184. DOI:10.1007/BF02521734.

11. Karnaukhova E, Ophir Y, Trinh L, Dalal N, Punt PJ, Golding B, et al. Expersion of human $\alpha 1$-proteinase inhibitor in Aspergillus niger. Microb Cell Fact. 2007;6(34):1-10. DOI: 10.1186/14752859-6-34.

12. Chill L, Trinh L, Azadi P, Ishihara M, Sonon R, Karnaukhova E, et al. Production, purification, and characterization of human $\alpha 1$ proteinase inhibitor from Aspergillus niger. Biotechnol Bioeng. 2009;102(3):828-44.DOI: 10.1002/bit.22099.

13. Majdi S, Sahebghadam Lotfi A, Papi S, Forouzandeh Moghadam M, Joneidi Z, Memari F, et al. Sepration and Optimization of Alpha1-Antitrypsin Properties in Saccharomyces Yeast. Euro J Zool Res. 2013;2:36-43.ISSN: 2278-7356.

14. Choi JH, Keum KC, Lee SY. Production of recombinant proteins by high cell density culture of Escherichia coli. Chem Eng Sci. 2006;61(3):876-85.DOI: 10.1016/j.ces.2005.03.031.

15. Papaneophytou CP, Kontopidis G. Statistical approaches to maximize recombinant protein expression in Escherichia coli: A general review. Protein Expr Purif. 2014;94:22-32. DOI:10.1016/j.pep.2013.10.016.

16. Cos O, Ramon R, Montesinos JL, Valero F. Operational strategies, monitoring and control of heterologous protein production in the methylotrophic yeast Pichia pastoris under different promoters: a review. Microb Cell Fact. 2006;5:17. DOI:10.1186/1475-2859-5-17.

17. d'Anjou MC, Daugulis AJ. Mixed-feed exponential feeding for fed-batch culture of recombinant methylotrophic yeast. Biotechnol Lett. 2000;22(5):341-6. DOI: 10.1023/A:1005612415737.

18. Stanbury PF, Whitaker A, Hall SJ. Principles of Fermentation Technology: Elsevier Science; 2013.

19. Bahrami A, Shojaosadati SA, Khalilzadeh R, Farahani EV. Twostage glycerol feeding for enhancement of recombinant hG-CSF production in a fed-batch culture of Pichia pastoris. Biotechnol Lett. 2008;30(6):1081-5. PMID: 18246301.

20. Yegane-Sarkandy S, FarnoudAM, Shojaosadati SA, Khalilzadeh $\mathrm{R}$, Sadeghyzadeh M, Ranjbar B, et al. Overproduction of human interleukin-2 in recombinant Escherichia coli BL21 high-cell-density culture by the determination and optimization of essential amino acids using a simple stoichiometric model. Biotechnol Appl Biochem. 2009;54(1):31-9. DOI:10.1042/ BA20080300.

21. Maghsoudi A, Hosseini S, Shojaosadati SA, VasheghaniFarahani E, Nosrati M, Bahrami A. A new methanol-feeding strategy for the improved production of $\beta$-galactosidase in high cell-density fed-batch cultures of Pichia pastoris Mut+ strains. Biotechnol. Bioprocess Eng.. 2012;17(1):76-83. DOI 10.1007/ s12257-011-0201-9.

22. Arjmand S, Bidram E, Lotfi AS, Shamsara M, Mowla
SJ. Evaluating the experssion level of biologically active recombinant human alpha1-antitrypsin in Pichia pastoris. Electron. J. Biotechnol. 2013;16(1). DOI: 10.2225.

23. Naresh M, Das S, Mishra P, Mittal A. The chemical formula of a magnetotactic bacterium. Biotechnol Bioeng. 2012;109(5):120516. DOI:10.1002/bit.24403.

24. Emmanuel ES, Ananthi T, Anandkumar B, Maruthamuthu S. Accumulation of rare earth elements by siderophore-forming Arthrobacter luteolus isolated from rare earth environment of Chavara, India. J Biosci. 2012;37(1):25-31.PMID: 22357200.

25. Wang J, Nguyen V, Glen J, Henderson B, Saul A, Miller LH. Improved yield of recombinant merozoite surface protein 3 (MSP3) from Pichia pastoris using chemically defined media. Biotechnol Bioeng. 2005;90(7):838-47. DOI:10.1002/bit.20491.

26. Jung DU, Yoo HY, Kim SB, Lee JH, Park C, Kim SW. Optimization of medium composition for enhanced cellulase production by mutant Penicillium brasilianum KUEB15 using statistical method. J. Ind. Eng. Chem.. 2015;25:145-50. DOI: $10.1016 /$ j.jiec.2014.10.026.

27. Ghosalkar A, Sahai V, Srivastava A. Optimization of chemically defined medium for recombinant Pichia pastoris for biomass production. Bioresor Technol. 2008;99(16):7906-10. DOI:10.1016/j.biortech.2008.01.059.

28. Moteshafi H, Hashemi M, Mousavi SM, Mousivand M. Characterization of produced xylanase by Bacillus subtilis D3d newly isolated from apricot phyllosphere and its potential in pre-digestion of BSG. J. Ind. Eng. Chem. 2016;37:251-60. DOI:10.1016/j.jiec.2016.03.036.

29. Kennedy M, Krouse D. Strategies for improving fermentation medium performance: a review. J Ind Microbiol Biotechnol. 1999;23(6):456-75. DOI: 10.1038/sj.jim.2900755.

30. Walker GM. Metals in Yeast Fermentation Processes. $A d v$ Appl Microbiol. 2004; 54:197-229. DOI: 10.1016/S00652164(04)54008-X.

31. Dombek KM, Ingram LO. Magnesium limitation and its role in apparent toxicity of ethanol during yeast fermentation. Appl Environ Microbiol. 1986;52(5):975-81.PMCID: PMC239160.

32. Udeh HO, Kgatla TE. Role of magnesium ions on yeast performance during very high gravity fermentation. J. Brew Distilling. 2013;4(2):19-45. DOI: 10.5897/JBD2013.0041.

33. Zhang D, Qin Y. The paradox of elongation factor 4: highly conserved, yet of no physiological significance. Biochem $J$. 2013;452(2):173-81.DOI: 10.1042/BJ20121792.

34. Romero-Gil V, Rejano-Zapata L, Garrido-Fernández A, ArroyoLópez FN. Effect of zinc formulations, sodium chloride, and hydroxytyrosol on the growth/no-growth boundaries of table olive related yeasts. Food Microbiol. 2016;57:71-80. DOI:10.1016/j.fm.2016.01.007.

35. Plantz BA, Nickerson K, Kachman SD, Schlegel VL. Evaluation of metals in a defined medium for Pichia pastoris expressing recombinant beta-galactosidase. Biotechnol Prog. 2007;23(3):687-92. DOI:10.1021/bp060332t. 